the boundary conditions can be obtained by the aid of the P. of L. A. ; and if the application of this principle leads to results which are dynamically unsound or impossible, the original hypothesis is vitiated even though the formulæ to which it leads should be found to agree with experiment. To endeavour to explain some new phenomenon by introducing a hypothetical term into the energy function, and to deduce the equations of motion and the boundary conditions by means of the P. of L. A., is perfectly legitimate as a tentative process; but the results thereby obtained require careful examination in order to ascertain whether or not they violate any of the fundamental principles of dynamics.

In some theories on the action of magnetism on light, the nypothetical term introduced into the energy function gives rise to certain additional terms in the equations, by means of which the motion and forces are specified, which make some of the forces discontinuous at the surface of separation of two different media. Theories of this kind consequently violate Newton's third law of motion, and can at best be only regarded as stop-gaps until some better theory has been discovered. On the other hand, the introduction of hypothetical terms into the equations which determine the forces, or some of them, may lead to-an energy function which fails to reproduce the original expressions for the forces when the P. of L. A. is applied; and in cases of this kind the principle affords a valuable test of the correctness of the previous work. The principle, like a great many other mathematical theorems, has its uses, but to convert it into a "graven image" is to court disaster. A. B. BASSET.

Fledborough Hall, Holyport, Berks, January 30.

\section{The Horny Membrane of Neohelia porcellana.}

Two years ago, Miss Edith Pratt published in vol. v. of Willey's "Zoological Results" a paper on the anatomy of Neohelia porcellana. In this paper attention was directed to a horny membrane lining the hollow tube which forms the axis of the colony, and the suggestion was made that this horny membrane is secreted by the Neohelia itself. The single specimen which Miss Pratt had to investigate was, unfortunately, a small one, and in the criticisms which appeared some doubts were expressed as to whether this horny membrane was not secreted by some tubicolous worm which formerly inhabited the hollow tube of the corallum, and not by the Neohelia itself. I have recently had the opportunity of examining specimens of two species of the closely related genus Amphihelia, one (A. oculata) from a depth of 240 fathoms off the coast of Florida, the other (A. ramea) obtained by H.M.S. Porcupine in the Faeroe Channel, 363 fathoms. In both of them there is a horny membrane similar in character and position to that described for Neohelia. Now it is difficult to believe that a worm forming the same kind of tube, with the same habit of mysteriously disappearing when the corals are preserved, occurs in such widely separated districts as Florida, deep water, Nęw Britain, shallow water, and the Faeroe Channel, deep water. The only reasonable conclusion is that these madrepores do actually secrete this horny membrane them selves. SYDNEY J. HICKSON.

Owens College, Manchester, February 2.

\section{Genius and the Struggle for Existence.}

Mr. Bulman, in Nature of January 22, urges that what is good for the individual or race will survive unaided. But surely this is contrary to well-known facts. Man, with the increase of specialisation, which (whether it be an unmixed good or no) we find associated with his advance to a greater mastery over the rest of Nature, has become, so to speak, a polymorphic species, like the ants, bees or termites; and while in all species we find more or less mutual aid, in polymorphic species it is especially obvious that it is not the isolated individual types, but the total combination that natural selection regards, since the isolated types may be quite incapable of reproducing their kind and performing their special duties unaided.

In all such cases; the "survival " of the individual types, and of the community as a whole, depends, not on the competence of individuals to survive unaided, but on the recognition, instinctive or conscious, of each other's value, and the resulting mutual aid, given either under instinct or in conscious exchange. Now, as I understand, Sir O. Lodge has simply pleaded that steps be taken which, while (pace Mr. Bulman) not interfering one whit with the education of the 9999 , shall lead to the recognition of the one exceptional genius, with a view to mutual aid, i.e. so that he may be set free to do the work of pioneer and leader, which he alone can do; and early, because ars longa, vita brevis.

We know that genius can be reared in night-schools, and about Palissy the potter; but ought we to count on our potter burning his furniture for our good, if we, with plenty of ordinary fuel, deny it him?

In the essay to which he refers in his letter in Naturf of January 29, Dr. Wallace attaches less importance to the rearing of a few men of exceptional qualities than to the weeding out of the worst and raising the average; but surely, without giving undue and exclusive credit for advance to the pioneers and prophets, we may take it that men like Darwin and Wallace himself, to mention only one type, will, under natural selection, render the later more conscious steps of man's evolution easier.

Dr. Wallace, in the letter referred to, speaks of the " fittest" not surviving under existing civilisation, meaning that many of the specialised types, which form important elements in our polymorphic communities, are not fittest to survive, and continue to reproduce their kind in more primitive or more ideal communities. But this, of course, accords well with the principle of the "survival " of those types "fittest" to the actual environment. (Survival, of course, does not postulate direct reproduction any more than it postulates long life; the "worker" bees "sur. vive.") Further, Dr. Wallace's hopeful attitude shows that he really trusts " natural selection" to steer the best races of man to a point whence their further, more selfconscious, progress (still, as always, under natural selection) will be more and more in accord with Nature's will, and so less wasteful and pain-fraught.

Man is a self-conscious part of Nature, with the power to "look before and after" ; and doubtless the races of man, which will rise highest under natural selection, will not let their faculty of taking counsel from natural and human history rest idle; but, just as Dr. Wallace himself showed years ago that "sexual selection," in the sense of choice of mates, had no power at all against "natural selection" (such selection being, I would say, of a faculty or instinct developed by natural selection, and from time to time modified by natural selection to suit changes in the environment), so this conscious "human selection" is but a faculty of man that is being developed (indirectly, perhaps) by natural selection, and can have no power at all to thwart " natural selection," though its wise use may save our race much of the pain that results from fruitlessly "kicking against the pricks."

G. W. BUTLER.

February 3.

It is, of course, true that genius has no survival-value in the struggle for existence between individuals or against physical conditions. But the case is very different when we come to the struggle between groups-tribes, village communities or nations. A tribe which produces a fine bard has far more fighting power than a tribe which has no singer. The possession of a noble literature makes England far more formidable than she otherwise would be. And from the days of flint instruments until now, the inventor has been the salvation of his people.

F. W. Headley.

\section{Remarkable Meteorological Phenomena in Australia.}

ON Wednesday, November 13.1902, we experienced here in Australia some most extraordinary neteorological phenomena. For the previous five or six days, exceedingly hot, dry weather had prevailed, owing to winds blowing from the Australian interior, where a huge anticyclone was resting, in a coastward

No. 1737 , vOL. 67$]$ 